peared. It would seem, therefore, that its eggs may be laid very late in the fall.

We are still working on the locust borer (Cyllene robinio) and have some problems connected with its injuries and ecology to work out during the season now opening.

\title{
AN APHIS PARASITE FEEDING AT PUNCTURE HOLES MADE BY THE OVIPOSITOR
}

By L. P. Rockwood, U. S. Bureau of Entomology, Forest Grove, Oregon

Having had my attention called by Dr. L. O. Howard to the fact that probably no observation has yet been published on any parasite of an aphis feeding on the juices of the host at puncture holes made by the ovipositor, I present the following observation as of interest for this reason.

On September 8, 1916, while examining red clover stems infested with Aphis bakeri Cowen, an Aphelinus, previously reared from this aphis and recently described by Dr. L. O. Howard in the Proceedings of the Biological Society of Washington, vol. 30, p. 77, as Aphelinus lapisligni $\mathrm{n}$. sp., was found in the midst of a colony of $A$. bakeri beneath a bract on a clover stem. The Aphelinus was observed to approach a medium-sized aphis which was feeding. The parasite examined the aphis with its antennæ, then walked away about its own length, turned its back to the aphis and exserted its long semi-transparent ovipositor which it plunged into the aphis, a little to one side of the anus. The Aphelinus kept its ovipositor inserted during a space of several seconds, and during that time backed up toward the aphis, apparently plunging the ovipositor deeper into the wound. The aphis showed some discomfort and excreted a drop of honey dew from the anus. The parasite concluded its operation, walked off a few of its own lengths and returned to repeat the performance during a much shorter period. The operation was repeated three times while under observation, the ovipositor being inserted cach time in approximately the same place. Then the Aphelinus returned and placed its mouth to the wound, and apparently fed on the juices of the aphis for more than a minute. The aphis was not dissected so it is not known whether one or more eggs were laid in the aphis.

For instances of this feeding habit with other parasitic Hymenoptera and other hosts, consult the paper entitled "On the Habit with Certain Chalcidoidea of Feeding at Puncture Holes made by the Ovipositor," by L. O. Howard, Journal of Economic Entomology, vol. III, No. 3, June, 1910, pages 357-360. 